\title{
Preparation of MOF Derived Zn-Co-C Composite as Anode for Lithium-ion Batteries
}

\author{
Mingyuan Ren ${ }^{1}$, Honghai Xu' ${ }^{2}$, Guoxu Zheng ${ }^{1}$, Xiaowei Han ${ }^{3, *}$ \\ ${ }^{1}$ School of software and microelectronics, Harbin University of Science and Technology, Harbin \\ 150080, P. R. China \\ ${ }^{2}$ School of science, Harbin University of Science and Technology, Harbin 150080, P. R. China \\ ${ }^{3}$ School of Computer and Information Engineering, Harbin University of Commerce, Harbin 150028, \\ P. R. China \\ *E-mail: hanxiaowei2017@163.com
}

doi: $10.20964 / 2020.08 .56$

Received: 22 January 2020 / Accepted: 9 May 2020 / Published: 10 August 2020

\begin{abstract}
This paper focuses on the preparation of hollow mixed metal oxide materials by means of mixed metal atom doping. In this paper, the hollow core-shell structure Zn-Co-MOFs material was prepared by hydrothermal method, calcined into $\mathrm{Zn}-\mathrm{Co}-\mathrm{C}$ material, and its conductivity and electrochemical performance were improved on the basis of retaining hollow core-shell channel structure. Hollow coreshell structure to avoid direct contact with the electrode materials and electrolyte, reduce the electrolyte decomposition, a loop to form porous channel structure, shorten the lithium ion diffusion path and improve the lithium storage capacity, core-shell structure ACTS as a skeleton structure, effectively relieve internal stress changes, the structure of the electrode material volume change and destruction, reduce capacity attenuation. The $\mathrm{Zn}-\mathrm{Co}-\mathrm{C}$ composite has a discharge specific capacity of $1749 \mathrm{mAh} \mathrm{g}^{-1}$ in the first coil and a maximum coulomb efficiency of $99.8 \%$. At $200 \mathrm{~mA} \mathrm{~g}^{-1}$ current density, the reversible capacity is up to $704 \mathrm{mAh} \mathrm{g}^{-1}$ at 200 cycles, and the multiplier and impedance are also excellent.
\end{abstract}

Keywords: MOFs, Mixed metal oxide, LIBs, electrode materials

\section{FULL TEXT}

(C) 2019 The Authors. Published by ESG (www.electrochemsci.org). This article is an open access article distributed under the terms and conditions of the Creative Commons Attribution license (http://creativecommons.org/licenses/by/4.0/). 